\title{
Association of free testosterone and sex hormone binding globulin with metabolic syndrome and subclinical atherosclerosis but not blood pressure in hypertensive perimenopausal women
}

\author{
Agnieszka Olszanecka, Kalina Kawecka-Jaszcz, Danuta Czarnecka
}

First Department of Cardiology, Interventional Electrocardiology and Hypertension, Jagiellonian University Medical College, Krakow, Poland

Submitted: 13 May 2015

Accepted: 20 August 2015

Arch Med Sci 2016; 12, 3: 521-528

DOI: 10.5114 /aoms.2016.59925

Copyright $\odot 2016$ Termedia \& Banach

\section{Abstract}

Introduction: Data on the role of androgens as potential mediators of increasing cardiovascular risk in women at midlife are controversial. The aim of the study was to analyze the relationship of free testosterone (FT) and sex hormone binding globulin (SHBG) with blood pressure and subclinical organ damage and metabolic syndrome (MS) in middle aged hypertensive women. Material and methods: One hundred and fifty-two women with newly diagnosed arterial hypertension were included in the study. In all subjects blood pressure measurements were performed as well as echocardiographic examination with left ventricular structure and function assessment (GE Vivid 7.0), carotid ultrasound with measurement of intima-media thickness (IMT), and carotid-femoral pulse wave velocity (PWV) measurement (Sphygmocor). A fasting blood sample was taken to measure glucose and lipid concentrations. Serum testosterone and SHBG were measured. Free testosterone was calculated according to the Vermeulen formula. Metabolic syndrome was defined following the International Diabetes Federation (IDF) recommendations. Results: Free testosterone was significantly higher and SHBG lower in women with MS independently of menopausal status. The odds ratio of MS per quartile increment in FT after adjustment for covariates was $2.06(95 \% \mathrm{Cl}$ : 1.16-3.65). There was no correlation between FT, SHBG and blood pressure. Free testosterone was associated with decreased left ventricular diastolic function (E/A ratio $\beta=-0.19, p=0.05$ ) and subclinical atherosclerosis (IMT $\beta=0.34, p=0.009$ ), but not arterial stiffness.

Conclusions: Free testosterone and SHBG independently of menopause status are related to MS. Free testosterone is associated with worse metabolic profile, subclinical atherosclerosis and impaired diastolic function of the left ventricle.

Key words: testosterone, women, metabolic syndrome, hypertension.

\section{Introduction}

Cardiovascular disease affects men and women differently, with women having later onset of disease, with rapid increase of cardiovascular risk with the onset of menopause. Hypertension is a major cardiovascular risk factor possibly explaining the excessive cardiovascular morbidity and mortality in postmenopausal women. During the transition from the

\author{
Corresponding author: \\ Agnieszka Olszanecka \\ First Department \\ of Cardiology \\ Interventional \\ Electrocardiology \\ and Hypertension \\ Jagiellonian University \\ Medical College \\ 17 Kopernika St \\ 31-501 Krakow, Poland \\ Phone: +48 124247300 \\ Fax: + 48124247320 \\ E-mail: olszanec@su.krakow.pl
}


premenopause to postmenopause state, many women also experience weight gain and central fat deposition [1]. It is likely that the enhanced cardiovascular risk in postmenopausal women is associated with metabolic syndrome (MS). Metabolic syndrome carries a fourfold higher risk of cardiovascular events in females than in males [2]. In a hypertensive female this risk may be partially mediated through an increased prevalence of hypertension-induced preclinical cardiovascular damage. Research has recently refocused interest on the cardiovascular role of androgens, shifting attention away from estrogens toward testosterone and sex hormone-binding globulin (SHBG) as potential mediators of increasing cardiovascular risk in women at midlife. In postmenopausal women androgens are unopposed by estrogen levels, but whether it plays a role in cardiometabolic risk modulation remains unclear.

Since androgen replacement therapy is increasingly being used for the treatment of sexual dysfunction and decreased well-being in postmenopausal women, its impact on lipid and metabolic parameters related to cardiovascular health should be studied thoroughly.

The aim of the study was to analyze the relationship of free testosterone (FT) and SHBG with blood pressure, hypertension-related subclinical organ damage and MS in hypertensive perimenopausal women.

\section{Material and methods}

\section{Study group}

We recruited consecutive female patients aged 40-60, who were referred to the Outpatient Clinic of the $1^{\text {st }}$ Department of Cardiology and Hypertension by general physicians with newly diagnosed, untreated mild to moderate hypertension to undergo 24-h ambulatory blood pressure monitoring (ABPM). Diagnosis of hypertension by general physicians was based on the office blood pressure measurements taken on two separate visits using semiautomatic, validated, oscillometric devices in accordance with European Society of Cardiology (ESC) and European Society of Hypertension (ESH) guidelines [3]. Hypertension was defines as average blood pressure equal to or exceeding $140 \mathrm{~mm} \mathrm{Hg}$ systolic or $90 \mathrm{~mm} \mathrm{Hg}$ diastolic. In all subjects 24-h ABPM (SpaceLabs 90210, SpaceLabs Inc., Redmond, Washington, USA), with blood pressure readings every $15 \mathrm{~min}$ during the day and every 20 min during the night, was performed in the Outpatient Clinic to confirm the diagnosis of sustained hypertension. Patients with surgical menopause, women using hormone replacement therapy or oral contraceptives, women with chronic kidney disease (defined as estimated glomerular filtration rate $<60 \mathrm{ml} / \mathrm{min} / 1.73 \mathrm{~m}^{2}$ ) and patients with diabetes mellitus were excluded from the study. The study group consisted of 152 women. All participants underwent a clinical assessment; a detailed history was taken using a standardized questionnaire and a physical examination with anthropometric measurements was performed. The definition of postmenopausal status was based on two criteria: self-reported menstrual characteristics (last menstruation > 1 year ago) confirmed by blood follicle stimulating hormone level (FSH) $>40 \mathrm{IU} / \mathrm{l}$. The study protocol was approved by the local ethics committee (KBET/51/B/2007).

\section{Methods}

All blood samples were taken during the follicular phase of the menstrual cycle in premenopausal women and arbitrarily in postmenopausal women. The levels of FSH and estradiol were measured using MEIA kits, Abbott (sensitivity $1 \mathrm{ng} / \mathrm{ml}$ for estradiol and $0.5 \mathrm{mlU} / \mathrm{ml}$ for FSH). Serum testosterone and SHBG were measured using the electrochemiluminescence immunoassay and Cobas immunoassay analyzers (Roche Diagnostics), with limits of detection at $0.087 \mathrm{nmol} / \mathrm{l}$ for testosterone and $0.800 \mathrm{nmol} / \mathrm{l}$ for SHBG. Concentrations of free and bioavailable testosterone were derived from total testosterone, SHBG and albumin concentration, calculated according to the Vermuelen formula [4]. Routine laboratory methods were applied for measurement of basic biochemical parameters. Metabolic syndrome was defined following the modified criteria of the International Diabetes Federation proposed in 2009 [5]. As all subjects included in the study were hypertensive, to diagnose MS at least two of the following criteria had to be fulfilled: waist circumference $>80 \mathrm{~cm}$; elevated triglyceride level $(\geq 1.7 \mathrm{mmol} / \mathrm{l})$; decreased $\mathrm{HDL}$ cholesterol (< $1.3 \mathrm{mmol} / \mathrm{l})$; and/or elevated fasting glucose concentration ( $\geq 100 \mathrm{mg} \%$ ).

\section{Assessment of subclinical organ damage}

Echocardiographic measurements were performed by one experienced observer, using a digital ultrasound system: GE Vivid 7 equipped with a 3.5-MHz transducer (General Electric Vingmed Ultrasound, Horten, Norway). As a measure of systolic function, dimensional fractional shortening was computed. For evaluation of diastolic function, mitral inflow velocities were recorded with pulsed-wave Doppler sonography. Carotid artery ultrasound with a high-resolution ultrasound scanner was performed with a high frequency (7 $\mathrm{MHz}$ ) linear array transducer (GE Vivid 7 General Electric Vingmed Ultrasound, Horten, Norway). The automated intima-media thickness (IMT) package from Vivid 7 was used. The IMT was mea- 
sured in the far wall of the common carotid artery at a $1 \mathrm{~cm}$ distance from the carotid bifurcation in a single frame during the end-diastolic phase. The presence of at least one carotid atherosclerotic plaque (defined as a focal thickening greater than $1.5 \mathrm{~mm}$ ) or diffuse intima-media thickening (the average common carotid wall thickness exceeding $0.9 \mathrm{~mm}$ ) was taken as evidence of vascular alterations.

The measurement of carotid-femoral pulse wave velocity (PWV) was performed using the SphygmoCor system (AtCor Medical, Sydney, Australia; Model MM3; software version 6.31). Detailed methodology of the assessment of subclinical organ damage has been published elsewhere [6].

\section{Statistical analysis}

Statistica 10.0 software was used for data management and statistical analysis (StatSoft, Statistica 10.0, Tulsa, Oklahoma, USA). The Shapiro-Wilk test was used to check the normality of distribution of analyzed variables. As the distributions of SHBG and FT concentrations were skewed, these values were log-transformed in order to improve normality for statistical testing. Continuous variables were compared by analysis of variance (ANOVA), using Student's $t$-test for dual comparisons. Analysis of categorical data was carried out by the $\chi^{2}$ test. Linear regression and multiple linear regression models were used to test the independent role of sex hormones and cardiometabolic risk factors and parameters of subclinical organ damage. Logistic regression models were performed in order to determine the odds ratio of the MS by quartiles of endogenous sex hormone levels. Models were adjusted for age. Since body mass index (BMI) is strongly associated with sex hormones as well as many MS components, analyses were repeated with additional adjustment for $\mathrm{BMI}$ as a continuous variable to control for confounding. The last model also included as a covariate menopausal status or estrogen concentration.

\section{Results}

\section{Study group characteristics}

Mean age of the study group was $51.0 \pm 3.5$ years. The prevalence of MS was $41 \%$ (63 patients). Characteristics of the study group in reference to the presence of MS are presented in Table I.

\section{Relationship between FT, SHBG and MS}

Women with MS, in both the premenopausal and postmenopausal group, had significantly higher FT concentration and lower SHBG concentration (Table II). Sex hormone binding globulin was significantly lower in postmenopausal compared to premenopausal women. There were no significant differences in FT concentration between pre- and postmenopausal females (Table II).

Analyzing the relationship between FT, SHBG and MS components, we found that the strongest association with FT was present for HDL cholesterol (Pearson's correlation coefficient: $r=-0.54$, $p<0.001)$, waist circumference $(r=0.24, p=0.03)$ and triglyceride concentration $(r=0.27, p=0.02)$. Body mass index showed a positive association with FT, which was of borderline statistical significance $(r=0.22, p=0.05)$. We did not observe a correlation between FT and fasting glucose concentration $(r=0.02, p=0.81)$ or blood pressure $(r=0.20, p=0.08)$. Similarly, SHBG did not correlate with blood pressure values $(r=-0.09, p=0.45)$, but correlated significantly with $\mathrm{HDL}$ cholesterol $(r=0.49, p<0.001)$, BMI $(r=-0.37, p<0.001)$, waist circumference $(r=-0.32, p=0.006)$ and triglyceride concentration $(r=-0.23, p=0.04)$.

The differences in MS components across quartiles of FT and SHBG are summarized in Tables III and IV. The increase in number of MS components was accompanied by higher concentration of FT (Figure 1). An opposite relationship was detected for SHBG concentration (Figure 2).

The odds ratio of MS per quartile increment in FT was 2.44 (95\% Cl: 1.43-4.14), and after adjustment for age, menopausal status and BMI it was still significant 2.06 (95\% Cl: 1.16-3.65). The odds ratio of MS per quartile decrement in SHBG was 2.18 (95\% Cl: 1.29-3.68), but after adjustment for age and BMI it lost its significance (adjusted odds ratio $1.68,95 \% \mathrm{Cl}$ : 0.97-3.05).

\section{Relationship between FT, SHBG and target organ damage}

Multivariate linear regression analysis revealed that FT independently of age, BMI, systolic blood pressure and menopausal status was inversely related to the parameter of left ventricular diastolic function (mitral inflow velocities E/A ratio) and subclinical atherosclerosis assessed by carotid IMT thickness (Table V). Including parameters of lipid profile in the multivariate analysis did not change the results. Left ventricular mass (LVM) and parameters of arterial stiffness were not related to testosterone concentration in the examined group (LVM indexed to height $r=0.05$, $p=0.63$; PWV $r=0.04, p=0.75$ ).

We observed a significant negative correlation between SHBG and LVM (correlation coefficient for LVM indexed to height: $r=-0.30, p=0.007$ ), and diastolic function (E/A: $r=0.33, p=0.002$ ) but not with vascular phenotypes (IMT: $r=-0.13$, $p=0.24$, PWV: $r=-0.15, p=0.21$ ). In multivariate linear regression analysis the relationship between SHBG and LVM was mainly BMI dependent. 
Table I. Clinical characteristics of the study group with reference to the presence of metabolic syndrome. Data are expressed as mean values \pm standard deviations (SD)

\begin{tabular}{|c|c|c|c|}
\hline \multirow[t]{2}{*}{ Parameter } & \multicolumn{2}{|c|}{ Metabolic syndrome } & \multirow[t]{2}{*}{$P$-value } \\
\hline & $\begin{array}{c}\text { No } \\
N=89\end{array}$ & $\begin{array}{c}\text { Yes } \\
N=63\end{array}$ & \\
\hline Age [years] & $50.9 \pm 2.4$ & $51.1 \pm 3.2$ & NS \\
\hline Postmenopausal, $n$ (\%) & $41(46.1)$ & $32(50.8)$ & NS \\
\hline Body weight [kg] & $69.2 \pm 9.7$ & $75.5 \pm 8.4$ & $<0.001$ \\
\hline Body height $[\mathrm{cm}]$ & $162.9 \pm 5.8$ & $162.6 \pm 4.8$ & NS \\
\hline BMI [kg/m²] & $26.0 \pm 3.2$ & $28.5 \pm 2.6$ & $<0.001$ \\
\hline Waist circumference $[\mathrm{cm}]$ & $83.6 \pm 8.4$ & $89.8 \pm 7.1$ & $<0.001$ \\
\hline Office SBP [mm Hg] & $151.0 \pm 12.6$ & $163.4 \pm 20.0$ & 0.03 \\
\hline Office DBP [mm Hg] & $89.0 \pm 10.6$ & $93.4 \pm 12.3$ & NS \\
\hline Heart rate $[/ \mathrm{min}]$ & $73.4 \pm 9.2$ & $78.1 \pm 10.3$ & 0.05 \\
\hline 24-h ABPM SBP [mm Hg] & $132.9 \pm 6.5$ & $133.9 \pm 8.5$ & NS \\
\hline 24-h ABPM DBP [mm Hg] & $81.2 \pm 6.8$ & $82.8 \pm 9.2$ & NS \\
\hline Glucose $[\mathrm{mmol} / \mathrm{l}]$ & $4.9 \pm 0.4$ & $5.3 \pm 0.6$ & $<0.001$ \\
\hline Total cholesterol [mmol/l] & $5.4 \pm 0.9$ & $5.7 \pm 0.9$ & $<0.0001$ \\
\hline LDL cholesterol [mmol/l] & $3.1 \pm 0.9$ & $3.4 \pm 0.7$ & 0.02 \\
\hline HDL cholesterol [mmol/l] & $1.7 \pm 0.3$ & $1.3 \pm 0.3$ & $<0.0001$ \\
\hline Triglycerides [mmol/ll] & $1.2 \pm 0.8$ & $2.3 \pm 1.2$ & $<0.0001$ \\
\hline Estradiol [pg/ml] & $59.8 \pm 65.2$ & $44.7 \pm 40.8$ & NS \\
\hline FSH [IU/I] & $41.4 \pm 37.7$ & $38.6 \pm 30.9$ & NS \\
\hline Total testosterone $[\mathrm{nmol} / \mathrm{l}]$ & $1.06 \pm 0.56$ & $1.30 \pm 0.83$ & 0.05 \\
\hline Free testosterone $[\mathrm{pmol} / \mathrm{l}]$ & $12.9 \pm 7.8$ & $22.36 \pm 16.7$ & 0.001 \\
\hline Log free testosterone $[\mathrm{nmol} / \mathrm{l}]$ & $1.00 \pm 0.30$ & $1.24 \pm 0.31$ & 0.001 \\
\hline SHBG [nmol/l] & $66.5 \pm 36.2$ & $40.6 \pm 20.1$ & 0.001 \\
\hline Log SHBG [nmol/l] & $1.77 \pm 0.21$ & $1.56 \pm 0.20$ & 0.001 \\
\hline
\end{tabular}

$B M I$ - body mass index, SBP - systolic blood pressure, DBP - diastolic blood pressure, ABPM - ambulatory blood pressure monitoring, FSH - follicle-stimulating hormone, SHBG - sex hormone binding globulin. P-value for Student's t-test for independent variables.

Diastolic function was age and BMI related, and in the model including these variables SHBG was excluded from factors significantly influencing $\mathrm{E} / \mathrm{A}$.

\section{Discussion}

The main finding of our study is a significant association of FT with MS, subclinical atherosclerosis and left ventricular diastolic function in middle aged women, independent of menopausal status. While hyperandrogenism is associated with the MS and increased risk of cardiovascular disease in premenopausal women with polycystic ovary syndrome [7], the relation between endogenous androgens and cardiovascular disease in postmenopausal women is complex. Serial mea- surements of testosterone in postmenopausal women showed that testosterone levels decrease after the menopause transition along with estradiol levels, but increased slowly with age in 9-year observation, such that by 70 years of age, the androgen levels were similar to levels found in premenopausal women [8]. The difference between pre- and postmenopausal women was that the androgen levels were unopposed by estrogen levels in postmenopausal women. Independently of menopausal status, in our study population increased FT was related to higher risk of MS. Among MS components the critical variables for this finding were the waist circumference, HDL concentration and triglyceride concentration. On the basis of our results we suggest that FT and 
Table II. Testosterone and SHBG concentration in pre- and postmenopausal women in relation to metabolic syndrome. Data are expressed as mean values \pm standard deviations (SD)

\begin{tabular}{|c|c|c|c|c|c|c|}
\hline \multirow[t]{3}{*}{ Parameter } & \multicolumn{2}{|c|}{ Premenopausal women } & \multirow[t]{3}{*}{$P$-value } & \multicolumn{2}{|c|}{ Postmenopausal women } & \multirow[t]{3}{*}{$P$-value } \\
\hline & $\begin{array}{c}\text { Metabolic } \\
\text { syndrome } \\
\text { No }\end{array}$ & $\begin{array}{c}\text { Metabolic } \\
\text { syndrome } \\
\text { Yes }\end{array}$ & & $\begin{array}{c}\text { Metabolic } \\
\text { syndrome } \\
\text { No }\end{array}$ & $\begin{array}{c}\text { Metabolic } \\
\text { syndrome } \\
\text { Yes }\end{array}$ & \\
\hline & $N=48$ & $N=41$ & & $N=31$ & $N=32$ & \\
\hline Total testosterone [nmol/l] & $1.19 \pm 0.53$ & $1.50 \pm 0.88$ & 0.04 & $0.93 \pm 0.56$ & $1.14 \pm 0.71$ & 0.07 \\
\hline Free testosterone [pmol/l] & $13.6 \pm 7.9$ & $22.2 \pm 13.0$ & 0.001 & $12.3 \pm 7.0$ & $22.4 \pm 9.0$ & 0.001 \\
\hline Log free testosterone $[\mathrm{nmol} / \mathrm{l}]$ & $1.05 \pm 0.29$ & $1.28 \pm 0.23$ & 0.02 & $0.97 \pm 0.37$ & $1.19 \pm 0.39$ & 0.05 \\
\hline SHBG $[\mathrm{nmol} / \mathrm{l}]$ & $76.0 \pm 42.5$ & $43.3 \pm 16.9$ & 0.01 & $57.7 \pm 27.0^{\star}$ & $38.2 \pm 22.1^{\wedge}$ & 0.02 \\
\hline Log SHBG [nmol/l] & $1.82 \pm 0.21$ & $1.62 \pm 0.16$ & 0.005 & $1.71 \pm 0.21$ & $1.52 \pm 0.23$ & 0.01 \\
\hline Estradiol [pg/ml] & $87.8 \pm 70.9$ & $72.4 \pm 44.3$ & NS & $19.5 \pm 17.3^{*}$ & $19.2 \pm 7.4^{\wedge}$ & NS \\
\hline FSH [IU/I] & $10.7 \pm 9.1$ & $12.3 \pm 10.7$ & NS & $74.9 \pm 26.9^{*}$ & $63.9 \pm 21.0^{\wedge}$ & NS \\
\hline
\end{tabular}

SHBG - sex hormone binding globulin, FSH - follicle-stimulating hormone. ${ }^{*} P$-value $<0.05$ vs. premenopausal without MS, $\wedge p$-value $<0.05$ vs. premenopausal with MS. P-value for Student's t-test for independent variables.

Table III. Metabolic syndrome components in quartiles of free testosterone concentration

\begin{tabular}{|lccccc|}
\hline $\begin{array}{l}\text { Free testosterone } \\
\text { quartiles }\end{array}$ & $\begin{array}{c}\text { Waist } \\
\text { circumference } \\
{[\mathrm{cm}]}\end{array}$ & $\begin{array}{c}\text { Systolic blood } \\
\text { pressure } \\
{[\mathrm{mm} \mathrm{Hg}]}\end{array}$ & $\begin{array}{c}\text { Triglyceride } \\
\text { concentration } \\
{[\mathrm{mmol} / \mathrm{l}]}\end{array}$ & $\begin{array}{c}\text { HDL cholesterol } \\
\text { concentration } \\
{[\mathrm{mmol} / \mathrm{l}]}\end{array}$ & $\begin{array}{c}\text { Glucose } \\
\text { concentration } \\
{[\mathrm{mmol} / \mathrm{l}]}\end{array}$ \\
\hline Q1 & $80.0 \pm 8.2$ & $151.4 \pm 10.9$ & $1.06 \pm 0.34$ & $1.70 \pm 0.34$ & $5.00 \pm 0.47$ \\
\hline Q2 & $84.6 \pm 9.7$ & $152.6 \pm 15.6$ & $1.21 \pm 0.54$ & $1.58 \pm 0.33$ & $4.91 \pm 0.58$ \\
\hline Q3 & $86.2 \pm 9.9$ & $154.6 \pm 17.8$ & $1.86 \pm 0.60$ & $1.47 \pm 0.24$ & $5.11 \pm 0.27$ \\
\hline Q4 & $92.0 \pm 8.7$ & $158.1 \pm 13.9$ & $1.94 \pm 0.76$ & $1.28 \pm 0.23$ & $5.43 \pm 0.55$ \\
\hline P-value & 0.02 & 0.27 & 0.02 & 0.004 & 0.30 \\
\hline
\end{tabular}

P-value for linear trend ANOVA analysis.

Table IV. Metabolic syndrome components in quartiles of SHBG concentration

\begin{tabular}{|lccccc|}
\hline SHBG quartiles & $\begin{array}{c}\text { Waist } \\
\text { circumference } \\
{[\mathrm{cm}]}\end{array}$ & $\begin{array}{c}\text { Systolic blood } \\
\text { pressure } \\
{[\mathrm{mm} \mathrm{Hg}]}\end{array}$ & $\begin{array}{c}\text { Triglyceride } \\
\text { concentration } \\
{[\mathrm{mmol} / \mathrm{l}]}\end{array}$ & $\begin{array}{c}\text { HDL cholesterol } \\
\text { concentration } \\
{[\mathrm{mmol} / \mathrm{l}]}\end{array}$ & $\begin{array}{c}\text { Glucose } \\
\text { concentration } \\
{[\mathrm{mmol} / \mathrm{l}]}\end{array}$ \\
\hline Q1 & $92.1 \pm 8.6$ & $159.9 \pm 13.1$ & $1.87 \pm 0.60$ & $1.28 \pm 0.24$ & $5.39 \pm 0.80$ \\
\hline Q2 & $87.4 \pm 10.3$ & $157.3 \pm 16.4$ & $1.74 \pm 0.50$ & $1.50 \pm 0.26$ & $5.04 \pm 0.30$ \\
\hline Q3 & $83.6 \pm 8.7$ & $150.0 \pm 17.1$ & $1.27 \pm 0.36$ & $1.55 \pm 0.33$ & $5.11 \pm 0.67$ \\
\hline Q4 & $79.7 \pm 8.0$ & $151.2 \pm 10.8$ & $1.02 \pm 0.52$ & $1.71 \pm 0.34$ & $4.79 \pm 0.34$ \\
\hline$P$-value & 0.01 & 0.41 & 0.01 & 0.005 & 0.03 \\
\hline
\end{tabular}

SHBG - sex hormone binding globulin. P-value for linear trend ANOVA analysis.

SHBG are strongly related to abdominal obesity. Data on the relationship between obesity and testosterone concentration in women are conflicting, with either an increase [9-12] or no change [1316] in BMI or waist circumference with increasing testosterone levels. The cross-sectional nature of most studies, including ours, rules out conclusions on cause-and-effect relationships. There are data suggesting that testosterone levels can be modulated in response to metabolic signals, rather than the opposite. Adipose tissue, with its 17b-hydroxysteroid dehydrogenase activity, has been suggested to be an important site of peripheral testosterone production [17, 18]. Moreover, studies analyzing the changes in testosterone after weight and body fat loss in overweight postmenopausal women showed that weight loss was followed by a significant decrease in testosterone concentration $[19,20]$. Conversely, studies examining the influence of testosterone treatment on changes in body composition showed an increase of body weight $[21,22]$. These observations are further supported by the data on the influence of testosterone administration on fat metabolism. In 


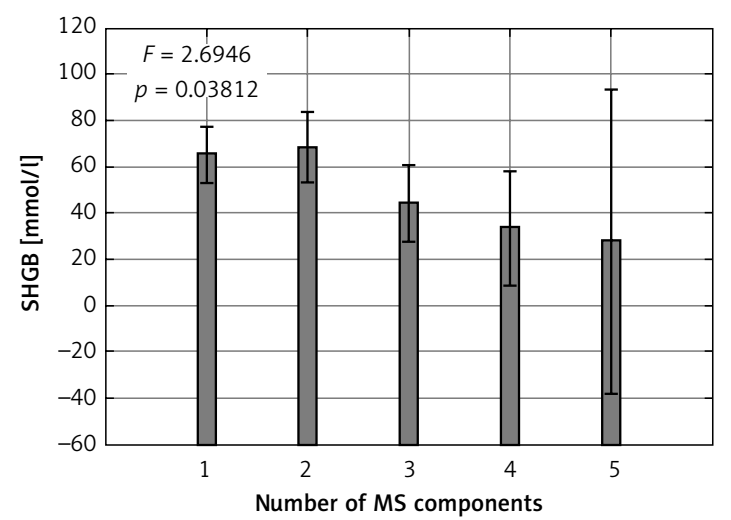

Figure 1. Number of metabolic syndrome components and SHBG concentration

$P$-value for linear trend ANOVA analysis.

Table V. Multiple linear regression models to test the predictive value of free testosterone for parameters of left ventricular diastolic function and carotid intima-media thickness

\begin{tabular}{|c|c|c|}
\hline \multirow[t]{2}{*}{ Variable } & \multicolumn{2}{|c|}{$\begin{array}{l}\text { Multiple linear } \\
\text { regression model }\end{array}$} \\
\hline & $\beta$ & $P$-value \\
\hline \multicolumn{3}{|l|}{ IMT: } \\
\hline $\begin{array}{l}\text { Free testosterone log } \\
(\log [\mathrm{ng} / \mathrm{ml}])\end{array}$ & 0.34 & 0.009 \\
\hline Age [years] & 0.41 & 0.003 \\
\hline $\mathrm{SBP}[\mathrm{mm} \mathrm{Hg}]$ & 0.33 & 0.001 \\
\hline $\mathrm{BMI}\left[\mathrm{kg} / \mathrm{m}^{2}\right]$ & 0.13 & 0.19 \\
\hline Menopause $(1-$ yes, $0-$ no) & -0.05 & 0.97 \\
\hline Coefficient of determination $R^{2}$ & \multicolumn{2}{|c|}{0.41} \\
\hline \multicolumn{3}{|l|}{ E/A: } \\
\hline $\begin{array}{l}\text { Free testosterone log } \\
(\log [\mathrm{ng} / \mathrm{ml}])\end{array}$ & -0.19 & 0.05 \\
\hline Age [years] & -0.23 & 0.07 \\
\hline $\mathrm{SBP}[\mathrm{mm} \mathrm{Hg}]$ & -0.06 & 0.53 \\
\hline $\mathrm{BMI}\left[\mathrm{kg} / \mathrm{m}^{2}\right]$ & -0.23 & 0.03 \\
\hline Menopause $(1-$ yes, $0-$ no $)$ & -0.22 & 0.09 \\
\hline Coefficient of determination $R^{2}$ & \multicolumn{2}{|c|}{0.38} \\
\hline
\end{tabular}

postmenopausal women oral administration of testosterone was associated with a decrease in hormone-sensitive lipase expression in subcutaneous fat tissue, which may explain the shift of fat accumulation towards the visceral abdominal area in this group of patients [23].

Contrary to our prediction, we did not observe a relationship between testosterone and blood pressure. The studies on associations between androgens and blood pressure in menopausal women brought inconsistent results. Similarly as in our group, Patel et al. [24] in a large group of

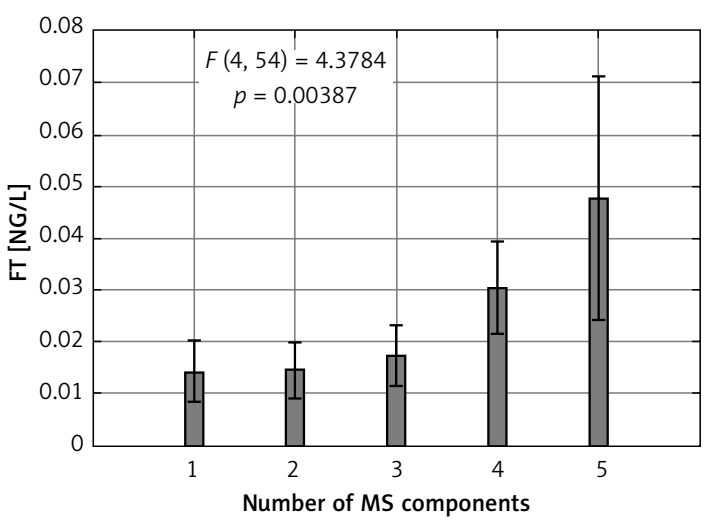

Figure 2. Number of metabolic syndrome components and free testosterone concentration $P$-value for linear trend ANOVA analysis.

postmenopausal women found a significant relationship between increased testosterone and MS, but blood pressure values across quartiles of testosterone concentration were comparable. In contrast, in the population-based sample of women, a positive association between total testosterone and blood pressure in cross-sectional and longitudinal analyses was shown [25]. It should be noted that in both in-vitro [26] and in-vivo [27] studies testosterone presents vasodilatory properties. This positive effect on vascular wall diameters can be attenuated by proatherogenic effects of testosterone, as observed in other studies. In vitro data suggest that testosterone may increase monocyte adhesion to the vascular endothelium [28]. Studies investigating the relation between testosterone and parameters of atherosclerosis in females have yielded contradictory results. Some studies found that higher levels of androgens and SHBG were associated with a reduced level of atherosclerosis [29-31]; however, others found a positive association between testosterone and indices of atherosclerosis [32, 33].

Our study gives further support to observations on the positive association between FT concentration and subclinical atherosclerosis.

There are only two studies examining the relationship of endogenous androgens with arterial stiffness in postmenopausal women. Creatsa et al. found that increased testosterone was associated with increase in arterial stiffness in women [34]. Another study in postmenopausal women on hemodialysis indicated a relationship between extremely low testosterone and increased vascular stiffness [35]. We did not find a relationship between arterial stiffness determined by carotid femoral pulse wave velocity and FT or SHBG. It cannot be excluded that the relationship between androgen concentration and arterial stiffness is U-shaped, but the limited data from observational studies in women do not allow us to draw conclusions. 
Increased left-ventricular mass is an important cardiovascular risk factor for morbidity and mortality. Available data revealed that the changes in left-ventricular mass in response to age and hypertrophic stimuli are different in men and women [36]. These differences are especially pronounced in people over 50 years old, in whom reproductive hormone concentrations have fallen. Only one study examined the relationship of sex hormones with heart structure in both sexes [37]. The authors, using MRI, assessed the cardiac mass and right ventricular performance in a large cohort free from cardiovascular disease. Higher levels of testosterone and dehydroepiandrostenedione were associated with greater right ventricular mass in men. In women there was no correlation of testosterone with cardiac mass. Sex hormone binding globulin showed a correlation with right ventricular mass in both sexes, but this association was attenuated and not statistically significant when fully adjusted for covariates. Similar data were obtained in our analyses. Testosterone did not show a relationship with left ventricular mass, while the relation of SHBG with left ventricular mass was BMI dependent.

In vitro studies show that estrogens have antiproliferative effects on cardiac fibroblasts [38] and vascular smooth-muscle cells [39], while testosterone increases proliferation of myocytes and fibroblasts [40].

The shift in estrogen to androgen ratio during the menopausal transition in hypertensive subjects characterized by the increased ventricular loading condition may predispose not only to changes in ventricular mass but also to ventricular compliance influencing diastolic function [41]. Analyzing the relationship between mitral inflow parameters, we found that FT was inversely related to diastolic function. To our knowledge, this is the first report on the relation of androgens in perimenopausal women with left ventricular diastolic function.

The present study has several limitations. The cross-sectional character of the study means that it can explain only associations, not causality. Second, as the study population consisted of mild and moderate hypertensive females, it is not enough to extrapolate our results to other groups. Third, we used automated electrochemiluminescence immunoassay for the quantification for total testosterone and SHBG, not liquid chromatography tandem mass spectrometry. Additionally, calculation of FT using the Vermeulen method may not correlate precisely with directly measured circulating FT. However, immunoassay of total testosterone and calculation of FT are widely accepted methods used in large studies, since measurement of total testosterone by mass spectrometry and FT by equilibrium dialysis is impractical.
In conclusion, in middle-aged hypertensive women independently of menopausal status free testosterone concentration is associated with increased risk of metabolic syndrome.

Free testosterone concentration is positively associated with parameters of subclinical atherosclerosis in the carotid artery and negatively with diastolic function of the left ventricle.

Whether FT is a marker or mediator of cardiovascular disease in this population merits further investigation.

\section{Conflict of interest}

The authors declare no conflict of interest.

\section{References}

1. Cifkova R, Pitha J, Lejskova M, Lanska V, Zecova S. Blood pressure around the menopause: a population study. J Hypertens 2008; 26: 1976-82.

2. Alberti KG, Eckel RH, Grundy SM, et al. Harmonizing the metabolic syndrome: a joint interim statement of the International Diabetes Federation Task Force on Epidemiology and Prevention; National Heart, Lung, and Blood Institute; American Heart Association; World Heart Federation; International Atherosclerosis Society; International Association for the Study of Obesity. Circulation 2009; 120: 1640-5.

3. Mancia G, Fagard R, Narkiewicz K, et al. 2013 Practice guidelines for the management of arterial hypertension of the European Society of Hypertension (ESH) and the European Society of Cardiology (ESC): ESH/ESC Task Force for the Management of Arterial Hypertension. J Hypertens 2013; 31: 1925-38.

4. Vermeulen A, Verdonck L, Kaufman JM. A critical evaluation of simple methods for the estimation of free testosterone in serum. J Clin Endocrinol Metab 1999; 84: 3666-72.

5. Alberti KG, Eckel RH, Grundy SM, et al. International Diabetes Federation Task Force on Epidemiology and Prevention. Harmonizing the metabolic syndrome: a joint interim statement of the International Diabetes Federation Task Force on Epidemiology and Prevention; National Heart, Lung, and Blood Institute; American Heart Association; World Heart Federation; International Atherosclerosis Society; and International Association for the Study of Obesity. Circulation 2009; 120: 1640-5.

6. Olszanecka A, Dragan A, Kawecka-Jaszcz K, Czarnecka D. Influence of metabolic syndrome and its components on subclinical organ damage in hypertensive perimenopausal women. Adv Med Sci 2014; 59: 232-9.

7. Cebeci F, Onsun N, Mert M. Insulin resistance in women with hirsutism. Arch Med Sci 2012; 8: 342-6.

8. Laughlin GA, Barrett-Connor E, Kritz-Silverstein D, von Mühlen D. Hysterectomy, oophorectomy, and endogenous sex hormone levels in older women: the Rancho Bernardo Study. J Clin Endocrinol Metab 2000; 85: 645-51.

9. Baglietto L, English DR, Hopper JL, et al. Circulating steroid hormone concentrations in postmenopausal women in relation to body size and composition. Breast Cancer Res Treat 2009; 115: 171-9.

10. Bezemer ID, Rinaldi S, Dossus L, et al. C-peptide, IGF-I, sex-steroid hormones and adiposity: a cross-sectional study in healthy women within the European Prospec- 
tive Investigation into Cancer and Nutrition (EPIC). Cancer Causes Control 2005; 16: 561-72.

11. Phillips GB, Jing T, Heymsfield SB. Does insulin resistance, visceral adiposity, or a sex hormone alteration underlie the metabolic syndrome? Studies in women. Metabolism 2008; 57: 838-44.

12. Weinberg ME, Manson JE, Buring JE, et al. Low sex hormone-binding globulin is associated with the metabolic syndrome in postmenopausal women. Metabolism 2006; 55: 1473-80.

13. Kaye SA, Folsom AR, Soler JT, Prineas RJ, Potter JD. Associations of body mass and fat distribution with sex hormone concentrations in postmenopausal women. Int J Epidemiol 1991; 20: 151-6.

14. Svendsen OL, Hassager C, Christiansen C. Relationships and independence of body composition, sex hormones, fat distribution and other cardiovascular risk factors in overweight postmenopausal women. Int J Obes Relat Metab Disord 1993; 17: 459-63.

15. Turcato E, Zamboni M, De Pergola G, et al. Interrelationships between weight loss, body fat distribution and sex hormones in pre- and postmenopausal obese women. J Intern Med 1997; 241: 363-72.

16. McTiernan A, Wu L, Chen C, et al. Women's Health Initiative Investigators. Relation of BMI and physical activity to sex hormones in postmenopausal women. Obesity 2006; 14: 1662-77.

17. Quinkler M, Sinha B, Tomlinson JW, Bujalska IJ, Stewart PM, Arlt W. Androgen generation in adipose tissue in women with simple obesity - a site-specific role for 17beta-hydroxysteroid dehydrogenase type 5. J Endocrinol 2004; 183: 331-42.

18. Corbould AM, Bawden MJ, Lavranos TC, Rodgers RJ, Judd SJ. The effect of obesity on the ratio of type 3 17beta-hydroxysteroid dehydrogenase mRNA to cytochrome P450 aromatase mRNA in subcutaneous abdominal and intraabdominal adipose tissue of women. Int J Obes Relat Metab Disord 2002; 26: 165-75.

19. Moran LJ, Noakes M, Clifton PM, Wittert GA, Belobrajdic DP, Norman RJ. C-reactive protein before and after weight loss in overweight women with and without polycystic ovary syndrome. I Clin Endocrinol Metab 2007; 92: 2944-51.

20. McTiernan A, Tworoger SS, Rajan KB, et al. Effect of exercise on serum androgens in postmenopausal women: a 12-month randomized clinical trial. Cancer Epidemiol Biomarkers Prev 2004; 13: 1099-105.

21. Zang H, Carlström K, Arner P, Hirschberg AL. Effects of treatment with testosterone alone or in combination with estrogen on insulin sensitivity in postmenopausal women. Fertil Steril 2006; 86: 136-44.

22. Huang G, Basaria S, Travison TG, et al. Testosterone dose-response relationships in hysterectomized women with or without oophorectomy: effects on sexual function, body composition, muscle performance and physical function in a randomized trial. Menopause 2014; 21: 612-23.

23. Zang H, Ryden M, Wahlen K, Dahlman-Wright K, Arner P, Linden Hirschberg A. Effects of testosterone and estrogen treatment on lipolysis signaling pathways in subcutaneous adipose tissue of postmenopausal women. Fertil Steril 2007; 88: 100-6.

24. Patel SM, Ratcliffe SJ, Reilly MP, et al. Higher serum testosterone concentration in older women is associated with insulin resistance, metabolic syndrome, and cardiovascular disease. J Clin Endocrinol Metab 2009; 94: 4776-84.
25. Ziemens B, Wallaschofski H, Völzke H, et al. Positive association between testosterone, blood pressure, and hypertension in women: longitudinal findings from the Study of Health in Pomerania. J Hypertens 2013; 31: 1106-13.

26. Yue P, Chatterjee K, Beale C, Poole-Wilson PA, Collins P. Testosterone relaxes rabbit coronary arteries and aorta. Circulation 1995; 91: 1154-60.

27. Montalcini T, Gorgone G, Gazzaruso C, Sesti G, Perticone F, Pujia A. Endogenous testosterone and endothelial function in postmenopausal women. Coron Artery Dis 2007; 18: 9-13.

28. McCrohon JA, Jessup W, Handelsman DJ, Celermajer DS. Androgen exposure increases human monocyte adhesion to vascular endothelium and endothelial cell expression of vascular cell adhesion molecule-1. Circulation 1999; 99: 2317-22.

29. Brand JS, van der Schouw YT. Testosterone, SHBG and cardiovascular health in postmenopausal women. Int J Impot Res 2010; 22: 91-104.

30. Bernini GP, Moretti A, Sgró M, et al. Influence of endogenous androgens on carotid wall in postmenopausal women. Menopause 2001; 8: 43-50.

31. Debing E, Peeters E, Duquet W, Poppe K, Velkeniers B, Van den Brande P. Endogenous sex hormone levels in postmenopausal women undergoing carotid artery endarterectomy. Eur J Endocrinol 2007; 156: 687-93.

32. Ouyang P, Vaidya D, Dobs A, et al. Sex hormone levels and subclinical atherosclerosis in postmenopausal women: the Multi-Ethnic Study of Atherosclerosis. Atherosclerosis 2009; 204: 255-61.

33. Braunstein GD, Johnson BD, Stanczyk FZ, et al. Relations between endogenous androgens and estrogens in postmenopausal women with suspected ischemic heart disease. J Clin Endocrinol Metab 2008; 93: 4268-75.

34. Creatsa M, Armeni E, Stamatelopoulos K, et al. Circulating androgen levels are associated with subclinical atherosclerosis and arterial stiffness in healthy recently menopausal women. Metabolism 2012; 61: 193-201.

35. Hayward CS, Webb CM, Collins P. Effect of sex hormones on cardiac mass. Lancet 2001; 357: 1354-6.

36. Ventetuolo CE, Ouyang P, Bluemke DA, et al. Sex hormones are associated with right ventricular structure and function: the MESA-right ventricle study. Am J Respir Crit Care Med 2011; 183: 659-67.

37. Shiraki N, Nakashima A, Doi S, et al. Low serum testosterone is associated with atherosclerosis in postmenopausal women undergoing hemodialysis. Clin Exp Nephrol 2014; 18: 499-506.

38. Dubey RK, Gillespie DG, Jackson EK, Keller PJ. 17Beta-estradiol, its metabolites, and progesterone inhibit cardiac fibroblast growth. Hypertension 1998; 31: 522-8.

39. Chen SJ, Li H, Durand J, Oparil S, Chen YF. Estrogen reduces myointimal proliferation after balloon injury of rat carotid artery. Circulation 1996; 93: 577-84.

40. Fujimoto R, Morimoto I, Morita $E$, Sugimoto $H$, Ito $Y$, Eto $S$. Androgen receptors, 5 alpha-reductase activity and androgen-dependent proliferation of vascular smooth muscle cells. J Steroid Biochem Mol Biol 1994; 50: 169-74.

41. Poręba R, Gać P, Poręba M, et al. Left ventricular diastolic dysfunction and plasma asymmetric dimethylarginine concentration in persons with essential hypertension. Arch Med Sci 2015; 11: 521-9. 